\section{National Chronic Obstructive Pulmonary Disease Awareness Month — November 2016}

Approximately 15.7 million U.S. adults have received a diagnosis of chronic obstructive pulmonary disease (COPD), which includes chronic bronchitis and emphysema (1). However, many more adults with symptoms of COPD, including frequent coughing, shortness of breath, excess phlegm or sputum production, wheezing, or difficulty taking a deep breath, might not be aware that they have COPD, or they may not be receiving treatment for COPD because they have never received a diagnosis. Geographic variations in the availability of primary care physicians and COPD specialists for the U.S. population suggest that 3.7 million adults do not have access to a pulmonologist within 50 miles; in many counties where patients have access to a pulmonologist within 50 miles, the COPD patient-to-pulmonologist ratio may exceed 6,000 (2). Therefore, early diagnosis, treatment, and management of COPD is dependent on adults communicating COPD symptoms to their primary care physician.

November is National COPD Awareness Month, an observance supported by the National Heart, Lung, and Blood Institute's campaign, "COPD: Learn More, Breathe Better." This year's theme, "Spotlight on COPD," will raise awareness about the signs and symptoms of COPD, and encourage persons with symptoms to speak to their physicians. More information about COPD is available at http://www.cdc.gov/ copd and http://www.nhlbi.nih.gov/health/educational/copd.

\section{References:}

1. Wheaton AG, Cunningham TJ, Ford ES, Croft JB. Employment and activity limitations among adults with chronic obstructive pulmonary disease-United States, 2013. MMWR Morb Mortal Wkly Rep 2015;64:289-95.

2. Croft JB, Lu H, Zhang X, Holt JB. Geographic accessibility of pulmonologists for adults with COPD: United States, 2013. Chest 2016;150:544-53. http://dx.doi.org/10.1016/j.chest.2016.05.014 